\title{
Sustainable Supply Chain Management Framework in a Higher Education Laboratory Using Intuitionistic Fuzzy Cognitive Map
}

\author{
Muhammad Ridwan Andi Purnomo ${ }^{1}$ (D), Adhe Rizky Anugerah ${ }^{2}$ (D), Bella Taradipa Dewipramesti ${ }^{1}$ (iD \\ ${ }^{1}$ Department of Industrial Engineering, Universitas Islam Indonesia (Indonesia) \\ ${ }^{2}$ Institute of Tropical Forestry and Forest Products (INTROP), Universiti Putra Malaysia (Malaysia) \\ ridwan_ie@uii.ac.id,adherizky02@gmail.com,bellataradipa@gmail.com
}

Received: May 2020

Accepted: June 2020

\section{Abstract:}

Purpose: This research aims to develop framework in the sustainable supply chain management (SCM) and to provide causal model of service industry specifically in higher education laboratory.

Design/methodology/approach: The concepts of sustainable SCM in higher education laboratory were obtained by in-depth interviews and organized using Delphi method. While to identify the relationship between concepts, intuitionistic fuzzy cognitive map was utilized.

Findings: As many as 15 concepts were identified to assess sustainability in the higher education laboratory SCM. These 15 concepts were classified into four categories according to its importance level, and there are two most important concepts: legal requirement and social responsibility. It is recommended for higher education laboratories to constantly obey national and regional government regulations and to satisfy current and prospective employers by providing work-ready graduates. This suggestion is expected to make higher education achieving its sustainability goals.

Originality/value: this research has identified factors that can help university laboratories achieve their sustainability by using combined methods. Greater and more accurate insight in determining the most important factor in the sustainable education can be identified.

Keywords: causal model, intuitionistic fuzzy cognitive map, laboratory, service supply chain, sustainable

\section{To cite this article:}

Purnomo, M.R.A., Anugerah, A.R., \& Dewipramesti, B.T. (2020). Sustainable supply chain management framework in a higher education laboratory using intuitionistic fuzzy cognitive map. Journal of Industrial Engineering and Management, 13(2), 417-429. https://doi.org/10.3926/jiem.3204

\section{Introduction}

Along with the development of economic globalization, service industries have increased rapidly and give positive contributions to economic growth for both developing and developed countries. In Indonesia, the contribution of service industries to gross domestic product increased from 45\% in 2011 to $54 \%$ in 2018. This indicates that several developing countries have shifted from product-based manufacturing to more service-based economies. 
The rapid growth of the service sector over the last 50 years has contributed to the need for innovation and increased service efficiency in order to fuel economic growth (Giannakis, 2011). However, the performance of the service industry was lower than that of the manufacturing sector (Cho, Lee, Ahn \& Hwang, 2012; van Ark, O'Mahony \& Timmer, 2008). One of the reasons is the ability of manufacturing industries to achieve higher performance in the Supply Chain Management (SCM) practices. Several researchers believe that SCM focus is heavily biased toward the manufacturing sector (Mirghafoori, Sharifabadi \& Takalo, 2018). Therefore, more attention should be given to the research and development of service supply chain management, since it becomes the major contributor for most of the developing and developed economies.

Education is one of an important sector in the service industry because of its contribution to socio-economic development. Investment and development in the education sector were expected to contribute more to poverty reduction. At a higher education level, one of the factors that determine the quality of the institutions is the research activities conducted in the laboratory. Similar to the manufacturing industry, the service industry should also have effective and efficient processes.

Laboratory is considered as a business unit as it delivers services to customers. In order to give excellent services to all stakeholders, there are 2 flows to be managed, which are backward flow; which is information flow, and forward flow, which is material flow. A laboratory must have a reliable supply chain system in order to have high accuracy of information and smooth material flow from material suppliers to customers. Moreover, strict environmental legislation and a high level of public knowledge of sustainability issues lead institutions to incorporate environmental and social responsibility issues into supply chain management (Saeed \& Kersten, 2019).

Companies, especially in developing countries, are beginning to adopt sustainable supply chain management as a rivalry requirement (Hussain, Khan \& Al-aomar, 2016). This is done to create, protect, and enhance the long-term environmental, social, and economic value of all stakeholders involved when delivering products or services to the market (Esfahbodi, Zhang \& Watson, 2016). Sustainable aspects in a supply chain aim to provide the best quality of products and services throughout the supply chain while still increasing effectiveness, reducing waste and costs. The dynamic and specific requirements in every supply chain make it difficult to solve in a sustainable way.

Given the broad range of services provided by the education sector, this research is focused on one unit: laboratory, since its contribution to teaching, learning, and research outputs of higher education. The aim of this research is to identify the concept or factor affecting the sustainability of the university laboratory supply chain and to provide a causal model of it. In order to achieve this objective, Intuitionistic Fuzzy Cognitive Map (IFCM) in the form of a causal model is commonly used. This methodology has been proven capable to identifying concepts and developing causal model to achieve sustainable supply chain in the health care industry (Mirghafoori et al., 2018).

Fuzzy Cognitive Map (FCM) is defined as a method for modelling complex systems and identifying relationships between criteria (Axelrod, 1976). FCM consists of several nodes that represent a criterion. In order to identify the relationships, the concept of intuitionistic fuzzy sets was developed to solve issues related to the doubts of experts on the basis of insufficient information available (Atanassov, 1986). In this research, criteria in the causal model were identified based on several expert opinions. Later, the criteria are called concept, and since the concepts have incomplete information, the IFCM method was implemented to construct the causal model.

\section{Literature Review}

\subsection{Causal Model}

The causal model is a model used to identify the relationship between concepts and how strong the concepts relationship is (Mirghafoori et al., 2018). The causal model is appropriate for events that can be conceptualized as processes that cause other events to trigger other processes. This structural modelling approach adopts the form of a directed graph, a causal effect diagram, to present the interrelationships and the values of the influential effect between groups (Tseng., Lin, Chen, Calahorrano Sarmiento \& Tan, 2019). The presence of causal interrelationships among criteria leads to obtain importance degree of each criteria (Dursun \& Gumus, 2020). This makes the causal model able to predict system behaviour. 


\subsection{Sustainable Service Supply Chain Management (SS-SCM)}

Service Supply Chain Management (S-SCM) is the management of information, processes, resources, and service performance from the initial supplier to the end customer (Hussain et al., 2016). The service supply chain consists of three basic units: the supplier, the service provider and the customer (Nouri, Nikabadi \& Olfat,, 2018). The addition of sustainable development ideas and services to the supply chain is called SS-SCM. It is about designing and managing supply chains from three dimensions that are environmental, economic, and social. The consideration of triple bottom line, the focus of sustainable service supply chain management (SSSCM) has become to optimize the whole service supply chain's economy, environment, and social performance (Liu, Bai, Liu \& Wei, 2017).

\subsection{Intuitionistic Fuzzy Cognitive Map}

This study uses a mixed method between FCM and IFS and called as IFCM. FCM is a graph containing nodes that represent the concept $\left(\mathrm{C}_{\mathrm{i}}\right)$ of the study domain, which relates to one another with weight axis $\mathrm{W}(\mathrm{i}, \mathrm{j})$ showing how concept $i$ is influenced by concept $j$. Intuitionistic Fuzzy Sets (IFS) could be considered as an approach if there is insufficient information available to define the inaccuracy of conventional fuzzy sets. Conventional fuzzy sets only consider the level of acceptance; however, IFS is characterized by the function of membership and nonmembership functions so that the second number of values is less than one. In this study, a triangular intuitionistic fuzzy number is used, as shown in Table 1 . The $\mu$ and $v$ signify the membership and non-membership degree respectively, and $\pi$ is called the degree of indeterminacy or hesitation ( $\mathrm{Lu} \& \mathrm{Ng}$, 2005).

\begin{tabular}{|l|c|}
\hline Linguistic Term & Intuitionistic Fuzzy Number $(\mu, \nu, \pi)$ \\
\hline No Influence & $(0.1,0.9,0)$ \\
\hline Very low influence & $(0.35,0.6,0.05)$ \\
\hline Low influence & $(0.5,0.45,0.05)$ \\
\hline High influence & $(0.75,0.2,0.05)$ \\
\hline Very high influence & $(0.9,0.1,0)$ \\
\hline
\end{tabular}

Table 1. Triangular Intuitionistic Fuzzy Number

\subsection{Related Publication}

Several researchers have conducted research in the area of service supply chain management, and most of them have discussed marketing and operational issues. In order to support the main objective, this section will focus on research in developing concepts or factors and the relationship between the concept to achieve sustainability in the service industry.

The framework for SS-SCM was developed using a literature review approach (Liu et al., 2017). There were 248 papers from 101 journals were analyzed and extracted to summaries the SSCM framework for both manufacturing and service industries. In the specificity of the service sector, the SSCM actors are suppliers, focal company and stakeholders (government, customer, NGOs, etc.). Focal companies were expected to do SSCM practices: sustainable supplier management, managing sustainability risks, and managing pressures and incentives.

The service sustainable supply chain framework in the Arab world, especially Abu Dhabi, has been constructed using confirmatory factor analysis (CFA) (Hussain et al., 2016). The research was taken in three industries: bank, airline, and hospital, with a total organization observed is 169 . There are four factors affecting sustainability in the service supply chain management: environmental management (with 4 indicators), social responsibility (with 3 indicators), health, safety, and risk management (with 3 indicators), and customer management (with 7 indicators). Furthermore, all those four factors have a strong correlation.

In the hospitality industry, factors influencing the sustainability of the service supply chain have been developed by using a combination of CFA and structural equation modelling (SEM) (Xu \& Gursoy, 2015). The constructed framework was linked to the customer's attitude and behaviors, including satisfaction, loyalty, and willingness to pay 
a premium for sustainable hospitality goods and services. The research was conducted in the US with 499 valid responses. There are three main factors influencing the sustainability in the hospitality SCM: environmental dimension (product design, service process, recycling, product management, etc.), social dimension (employees, customers, community, etc.), and economic dimension (cost control, revenue growth, etc.). The results found that environmental and economic dimensions positively influence customer satisfaction, loyalty, and willingness, while social dimension positively influences customer satisfaction and negatively influences customer willingness.

Besides, a sustainable supply chain framework has been developed in electronic manufacturing firms that focus on delivering design (Tseng, Lim, Wong, Chen \& Zhan, 2018). The research was conducted in Taiwan and started by developing a framework from the existing study. The Fuzzy Delphi Method (FDM) was utilized to validate the content of the constructed framework by asking the opinions of 10 professors and 20 management professionals; therefore, less important criteria could be eliminated. Furthermore, ANP is used to evaluate the interdependent relationships between variables. The results indicated that environmental service operation design in the topranking aspect should be considered.

FDM can also be joined with the balance scorecard (BSC) method (Nouri et al., 2019). The BSC is used to accommodate goals and integrate the business strategy with sustainability and SCM aspects. The objective of this research is to develop a SSCM framework in the hospitality industry. There were four dimensions to achieve sustainability in the hospitality industry: financial, supply chain stakeholders, learning growth, and innovation dimension. Twenty-three criteria under four dimensions were defined, and 2 criteria were deleted because of their low importance. Based on the results, every criterion is interrelated.

Integrating the Delphi method and IFCM method to develop the SS-SCM framework has been successfully done in the Iranian hospital industry (Mirghafoori et al., 2018). The framework was developed and selected through Delphi method by interviewing 18 experts in the hospital. The research was able to reorganize 68 initial concepts into 15 concepts. Furthermore, IFCM was used to select the most important concept to be prioritized. The results found that service delivery management is highly important among other concepts.

In this research, we proposed a framework in the university laboratory to achieve its sustainability in the supply chain. This research was started by reviewing several articles to develop the initial framework. Once the initial framework was established, we used the Delphi method to eliminate several irrelevant concepts. Lastly, the IFCM was utilized to understand the importance level of each concept.

\section{Methodology}

The main objective of this research is to develop SS-SCM in the Indonesian university laboratory and determine which concept has the highest importance level. A comprehensive research methodology is required to achieve this objective and has been developed in this section. The research methodology includes research materials, data collection methods, questionnaire development, and data analysis methods.

This research consists of primary data which collected through in-depth interviews and a survey questionnaire distributed to SCM and university laboratory experts and secondary data which obtained from an extensive literature review of SS-SCM and IFCM methods.

\subsection{Research Materials}

This research was conducted in the Industrial Statistics and Optimization Laboratory (later we called as SIOP), Islamic University of Indonesia, Yogyakarta. This is a well-known private university in Indonesia with total average enrollment is more than 26,000 annually. SIOP lab is a subunit of industrial engineering department with main activities are research, teaching, and social responsibility. SIOP Lab as the service industry has a supply chain, as shown in Figure 1.

There are two actors at the supplier level: the university department (study program) and laboratory material suppliers. The university department is a vital actor for laboratory, as the laboratory was developed under the department. The university department acts as the main source for research and development funding, and it has major control in giving approval of any lab activities. 


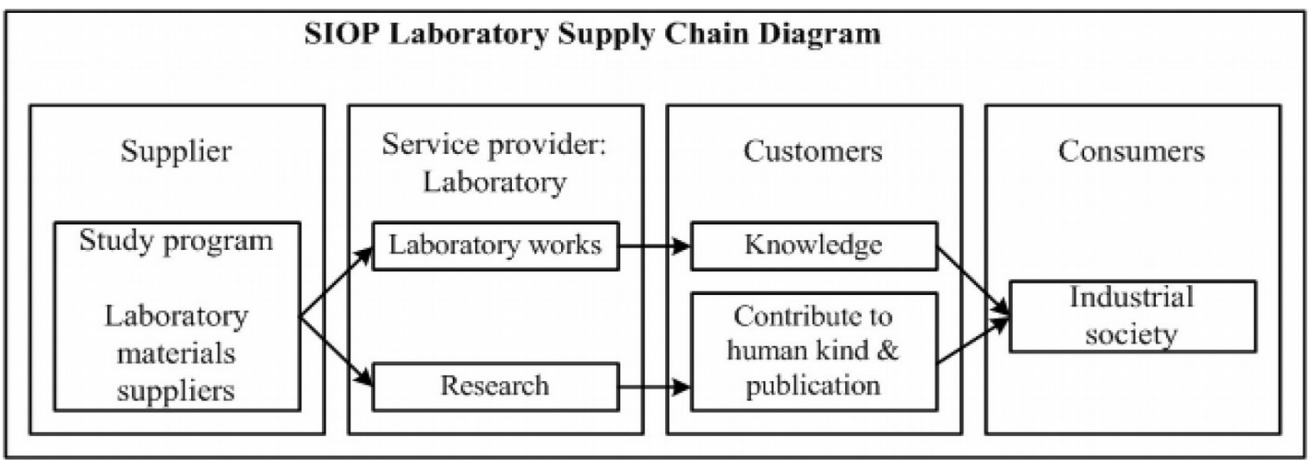

Figure 1. Laboratory Supply Chain

As a service provider, the SIOP lab does laboratory work and research. Every semester, at least one subject is taught by laboratory assistants and lecturers. Besides, this laboratory also provides help to undergraduate and postgraduate students to conduct their research, such as: data processing using data mining and statistical tools. Therefore, the output to its customers is knowledge and publication.

\subsection{Data Collection Method}

This research is initiated by developing a framework which derived from existing literature and in-depth interviews with experts. Once the initial framework has been constructed, the questionnaire is distributed to 7 experts who are the academic staffs in the department of industrial engineering, Islamic University of Indonesia. It consists of 4 laboratory heads with minimum master qualifications and 3 SCM experts with PhD in supply chain management. The questionnaire was given in two phases. The first phase questionnaire was developed to know the importance level of the indicators, and at this phase, experts were able to remove and or add other indicators. In the second phase, the experts were asked to give the influence level of each indicator.

\subsubsection{Questionnaire Development}

Most of the environmental and social indicators in this research were derived by Mirghafoori et al., (2018). While the economic indicators were derived from Cho et al., (2012) and Cooper and Ellram (1993). As many as 15 concepts that might influence sustainability in the laboratory supply chain have been collected. The Delphi method was used to reorganize the outputs, and it was carried out with the help of 7 experts. Table 2 shows the initial concepts and indicators for the laboratory supply chain management. The initial concepts were given to the experts to be graded according to their importance level. The experts rate the concepts according to their importance level as 1 (not important) to 3 (very important). Indicators with the lowest average score would be eliminated for the next questionnaire.

\begin{tabular}{|l|l|}
\hline Main Concepts & Indicators \\
\hline \multirow{4}{*}{ Information management (c1) } & Provide accurate information \\
\cline { 2 - 2 } & Numbers of information provided \\
\cline { 2 - 2 } Service management (c2) & Keep updated information \\
\cline { 2 - 2 } & Conform to standards and rules \\
\hline \multirow{5}{*}{ Energy consumption (c3) } & Speed of service delivery \\
\cline { 2 - 2 } & Keeping promises to students \\
\cline { 2 - 2 } & Lab assistant absenteeism \\
\cline { 2 - 2 } & Service provision cost \\
\hline & Water consumption \\
\cline { 2 - 2 } & Electricity consumption \\
\hline
\end{tabular}




\begin{tabular}{|c|c|}
\hline Main Concepts & Indicators \\
\hline \multirow{3}{*}{ Personnel (c4) } & Lab assistant satisfaction \\
\hline & Motivation and assistant development \\
\hline & Lab assistant capability and capacity \\
\hline \multirow{3}{*}{ Environment (c5) } & Attention to laboratory environment \\
\hline & Eco-friendly lab activities (e.g.: paperless) \\
\hline & Green Building \\
\hline \multirow{2}{*}{ Social responsibility (c6) } & Complaint handling \\
\hline & Responsive with student's complaint \\
\hline \multirow{3}{*}{ Community and stakeholder (c7) } & Interaction with stakeholders \\
\hline & Collaboration with stakeholders \\
\hline & Stakeholder satisfaction \\
\hline \multirow{4}{*}{ Demand management (c8) } & Grading transparency \\
\hline & Lab assistant schedule related to after-class discussion \\
\hline & Campus organization participation \\
\hline & Thesis discussion \\
\hline \multirow{3}{*}{ Financial management (c9) } & Use the financial allocation wisely \\
\hline & Cash flow rate \\
\hline & Use the research and teaching grant wisely \\
\hline \multirow{3}{*}{$\begin{array}{l}\text { Resource and capacity } \\
\text { management (c10) }\end{array}$} & Service capacity \\
\hline & Lab assistant training \\
\hline & Facility and resource management \\
\hline \multirow{3}{*}{$\begin{array}{l}\text { Research and Development } \\
\text { (C11) }\end{array}$} & Suitability of practicum modules \\
\hline & Lab assistant research output \\
\hline & Lab assistant participation in science competition \\
\hline \multirow{3}{*}{$\begin{array}{l}\text { Customer Relationship } \\
\text { Management (c12) }\end{array}$} & Students satisfaction \\
\hline & Information accessibility \\
\hline & Customer facing \\
\hline \multirow{2}{*}{$\begin{array}{l}\text { Supplier Relationship } \\
\text { Management (c13) }\end{array}$} & Lab assistant recruitment efficiency \\
\hline & Communication with suppliers \\
\hline \multirow{2}{*}{ Ethics (c14) } & Confidential information between students and lab assistant \\
\hline & Ethics code Elements are obeyed by all supply chain elements \\
\hline \multirow{2}{*}{ Legal requirement (c15) } & Government regulation regarding energy efficiency \\
\hline & Government regulation regarding waste \\
\hline
\end{tabular}

Table 2. Proposed framework in the laboratory supply chain

There were two indicators that were excluded in the survey attributes for the second phase: campus organization participation (under c8) and survey provision cost (under c2). This according to the Delphi method, distributed to 7 experts and all of them agreed to exclude those two indicators in the survey. 


\subsection{Data Analysis Method}

\subsubsection{Constructing the Intuitionistic Fuzzy Matrix of Success}

This is a $[\mathrm{n} \times \mathrm{m}]$ matrix, where $\mathrm{n}$ is the number of concepts in the sustainable laboratory supply chain management $\left(A_{i}\right)$ and $m$ represents the number of experts involved in this survey $\left(E_{k}\right)$. Determine $=\left[\mu_{i j}(x), v_{i j}(x), \pi_{i j}(x)\right]$; this represents the intuitionistic fuzzy degree of importance given by expert $j$ to concept $i$. The constructed matrix for this case is shown in Table 3.

\begin{tabular}{|c|c|c|c|c|}
\hline \multicolumn{5}{|c|}{ Expert } \\
\hline Concepts & 1 & 2 & $\ldots$ & 7 \\
\hline $\mathrm{C} 1$ & $\left(\begin{array}{llll}0.90 & 0.10 & 0.00\end{array}\right)$ & $\left(\begin{array}{lll}0.35 & 0.60 & 0.05\end{array}\right)$ & $\ldots$ & $\left(\begin{array}{llll}0.90 & 0.10 & 0.00\end{array}\right)$ \\
\hline $\mathrm{C} 2$ & $\left(\begin{array}{llll}0.90 & 0.10 & 0.00\end{array}\right)$ & $\left(\begin{array}{llll}0.50 & 0.45 & 0.05)\end{array}\right.$ & $\ldots$ & $\left(\begin{array}{llll}0.90 & 0.10 & 0.00)\end{array}\right.$ \\
\hline C3 & $\left(\begin{array}{llll}0.50 & 0.45 & 0.05)\end{array}\right.$ & $\left(\begin{array}{llll}0.90 & 0.10 & 0.00)\end{array}\right.$ & $\ldots$ & $\left(\begin{array}{llll}0.90 & 0.10 & 0.00)\end{array}\right.$ \\
\hline $\mathrm{C} 4$ & $\left(\begin{array}{llll}0.75 & 0.20 & 0.05)\end{array}\right.$ & $\left(\begin{array}{llll}0.50 & 0.45 & 0.05)\end{array}\right.$ & $\ldots$ & $\left(\begin{array}{llll}0.75 & 0.20 & 0.05\end{array}\right)$ \\
\hline $\mathrm{C} 5$ & $\left(\begin{array}{llll}0.50 & 0.45 & 0.05\end{array}\right)$ & $\left(\begin{array}{llll}0.90 & 0.10 & 0.00)\end{array}\right.$ & $\ldots$ & $\left(\begin{array}{llll}0.90 & 0.10 & 0.00)\end{array}\right.$ \\
\hline C6 & (0.35 0.600 .05$)$ & $\left(\begin{array}{llll}0.75 & 0.20 & 0.05)\end{array}\right.$ & $\ldots$ & $\left(\begin{array}{llll}0.75 & 0.20 & 0.05\end{array}\right)$ \\
\hline $\mathrm{C} 7$ & $\left(\begin{array}{llll}0.50 & 0.45 & 0.05\end{array}\right)$ & $\left(\begin{array}{llll}0.75 & 0.20 & 0.05)\end{array}\right.$ & $\ldots$ & $\left(\begin{array}{llll}0.75 & 0.20 & 0.05\end{array}\right)$ \\
\hline $\mathrm{C} 8$ & $\left(\begin{array}{llll}0.75 & 0.20 & 0.05)\end{array}\right.$ & $\left(\begin{array}{llll}0.50 & 0.20 & 0.30\end{array}\right)$ & $\ldots$ & $\left(\begin{array}{llll}0.90 & 0.10 & 0.00\end{array}\right)$ \\
\hline C9 & $\left(\begin{array}{llll}0.75 & 0.20 & 0.05\end{array}\right)$ & $\left(\begin{array}{llll}0.75 & 0.20 & 0.05)\end{array}\right.$ & $\ldots$ & $\left(\begin{array}{llll}0.75 & 0.20 & 0.05\end{array}\right)$ \\
\hline $\mathrm{C} 10$ & $\left(\begin{array}{llll}0.90 & 0.10 & 0.00\end{array}\right)$ & $\left(\begin{array}{llll}0.50 & 0.45 & 0.05)\end{array}\right.$ & $\ldots$ & $\left(\begin{array}{llll}0.75 & 0.20 & 0.05\end{array}\right)$ \\
\hline C11 & $\left(\begin{array}{llll}0.90 & 0.10 & 0.00\end{array}\right)$ & $\left(\begin{array}{llll}0.50 & 0.45 & 0.05)\end{array}\right.$ & $\ldots$ & $\left(\begin{array}{llll}0.75 & 0.20 & 0.05\end{array}\right)$ \\
\hline $\mathrm{C} 12$ & $\left(\begin{array}{llll}0.75 & 0.20 & 0.05)\end{array}\right.$ & 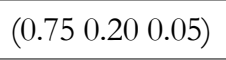 & $\ldots$ & $\left(\begin{array}{llll}0.90 & 0.10 & 0.00)\end{array}\right.$ \\
\hline C13 & $\left(\begin{array}{llll}0.75 & 0.20 & 0.05)\end{array}\right.$ & $\left(\begin{array}{llll}0.90 & 0.10 & 0.00)\end{array}\right.$ & $\ldots$ & $\left(\begin{array}{llll}0.90 & 0.10 & 0.00)\end{array}\right.$ \\
\hline $\mathrm{C} 14$ & $\left(\begin{array}{llll}0.75 & 0.20 & 0.05)\end{array}\right.$ & $\left(\begin{array}{llll}0.50 & 0.45 & 0.05)\end{array}\right.$ & $\ldots$ & $\left(\begin{array}{llll}0.75 & 0.20 & 0.05\end{array}\right)$ \\
\hline C15 & $\left(\begin{array}{llll}0.50 & 0.45 & 0.05\end{array}\right)$ & $\left(\begin{array}{llll}0.10 & 0.90 & 0.00\end{array}\right)$ & $\ldots$ &  \\
\hline
\end{tabular}

Table 3. Laboratory intuitionistic fuzzy matrix

\subsubsection{Constructing the Relationship Strength of Matrix of Success}

This is a $[n \times n]$ matrix where each element represents the relationship of concept $i$ with concept $j . S_{i j}$ value would be in the range of $[-1,1]$. This indicates the similarity level between concept $i$ and $j$, and it is measured by its distance. In this research, normalized Euclidean distance is used to measure the distance between concepts as shown in Eq 1. The Euclidean distance formula finds the distance between any two points in Euclidean vector. This distance can classify the sample based on the principle of minimum distance degree (Ke, Song \& Quan, 2018). The normalized Euclidean distance gives the best distance measure between $i$ and $j$ for its high rate of confidence in terms of accuracy. The relationship strength for this study is shown in Table 4.

\subsubsection{Constructing the Final Matrix of Success}

In this stage, the final matrix was constructed by referring to the previous matrix to avoid misleading of the data. In the final matrix, the relationship status between the matrix was defined. The negative value is expressed if two concepts are negatively correlated. The bigger the number, the stronger the relationship between concepts. The final matrix of success is shown in Table 5.

\subsubsection{Constructing the Graphical Representation of Intuitionistic Fuzzy Cognitive Map}

The results are plotted as an intuitionistic fuzzy cognitive map of critical success factors. There are two main components in the map: node and edge. Node represents the concepts, while the edge indicates their relationship status and is represented by an arrow. The relationship strength is also defined in the arrow. The arrow that is out 
from the node means concept $i$ affects concept $j$, while the arrow that is into the node means concept $i$ is affected by concept $j$.

$$
d(A, B)=\left\{\frac { 1 } { 2 n } \sum _ { i = 1 , j = 1 } ^ { n } \left[\left(\mu_{A}^{i}\left(x_{j}\right)-\left(\mu_{B}^{i}\left(x_{j}\right)\right)^{2}+\left(v_{A}^{i}\left(x_{j}\right)-v_{B}^{i}\left(x_{j}\right)\right)^{2}+\left(\Pi_{A}^{i}\left(x_{j}\right)-\left(\Pi_{B}^{i}\left(x_{j}\right)\right)^{2}\right]\right\}^{1 / 2}\right.\right.
$$

\begin{tabular}{cccccccccccccccc}
\hline & $\mathbf{C 1}$ & $\mathbf{C 2}$ & $\mathbf{C 3}$ & $\mathbf{C 4}$ & $\mathbf{C 5}$ & $\mathbf{C 6}$ & $\mathbf{C 7}$ & $\mathbf{C 8}$ & $\mathbf{C 9}$ & $\mathbf{C 1 0}$ & $\mathbf{C 1 1}$ & $\mathbf{C 1 2}$ & $\mathbf{C 1 3}$ & $\mathbf{C 1 4}$ & $\mathbf{C 1 5}$ \\
\hline C1 & - & 0.09 & 0.25 & 0.13 & 0.25 & 0.26 & 0.23 & 0.10 & 0.18 & 0.11 & 0.10 & 0.17 & 0.22 & 0.10 & 0.21 \\
$\mathbf{C 2}$ & 0.09 & - & 0.22 & 0.09 & 0.22 & 0.23 & 0.20 & 0.11 & 0.16 & 0.07 & 0.09 & 0.13 & 0.17 & 0.11 & 0.24 \\
$\mathbf{C 3}$ & 0.25 & 0.22 & - & 0.20 & 0.00 & 0.11 & 0.09 & 0.23 & 0.13 & 0.22 & 0.21 & 0.12 & 0.11 & 0.18 & 0.31 \\
C4 & 0.13 & 0.09 & 0.20 & - & 0.20 & 0.20 & 0.16 & 0.10 & 0.13 & 0.05 & 0.07 & 0.12 & 0.16 & 0.07 & 0.21 \\
C5 & 0.25 & 0.22 & 0.00 & 0.20 & - & 0.11 & 0.09 & 0.23 & 0.13 & 0.22 & 0.21 & 0.12 & 0.16 & 0.07 & 0.21 \\
C6 & 0.26 & 0.23 & 0.11 & 0.20 & 0.11 & - & 0.10 & 0.24 & 0.18 & 0.23 & 0.23 & 0.17 & 0.17 & 0.20 & 0.28 \\
C7 & 0.23 & 0.20 & 0.09 & 0.16 & 0.09 & 0.10 & - & 0.20 & 0.10 & 0.20 & 0.19 & 0.13 & 0.14 & 0.14 & 0.26 \\
C8 & 0.10 & 0.11 & 0.23 & 0.10 & 0.23 & 0.24 & 0.20 & - & 0.17 & 0.11 & 0.13 & 0.17 & 0.22 & 0.10 & 0.16 \\
C9 & 0.18 & 0.16 & 0.13 & 0.13 & 0.13 & 0.18 & 0.10 & 0.17 & - & 0.14 & 0.13 & 0.09 & 0.11 & 0.11 & 0.27 \\
C10 & 0.11 & 0.07 & 0.22 & 0.05 & 0.22 & 0.23 & 0.20 & 0.11 & 0.14 & - & 0.05 & 0.13 & 0.17 & 0.09 & 0.23 \\
C11 & 0.10 & 0.09 & 0.21 & 0.07 & 0.21 & 0.23 & 0.19 & 0.13 & 0.13 & 0.05 & - & 0.12 & 0.16 & 0.07 & 0.23 \\
C12 & 0.17 & 0.13 & 0.12 & 0.12 & 0.12 & 0.17 & 0.13 & 0.17 & 0.09 & 0.13 & 0.12 & - & 0.05 & 0.12 & 0.29 \\
C13 & 0.22 & 0.17 & 0.11 & 0.16 & 0.11 & 0.17 & 0.14 & 0.22 & 0.11 & 0.17 & 0.16 & 0.05 & - & 0.16 & 0.33 \\
C14 & 0.10 & 0.11 & 0.18 & 0.07 & 0.18 & 0.20 & 0.14 & 0.10 & 0.11 & 0.09 & 0.07 & 0.12 & 0.16 & - & 0.20 \\
C15 & 0.21 & 0.24 & 0.31 & 0.21 & 0.31 & 0.28 & 0.26 & 0.16 & 0.27 & 0.23 & 0.23 & 0.29 & 0.33 & 0.20 & - \\
\hline
\end{tabular}

Table 4. Relationship strength of the matrix of success

\begin{tabular}{cccccccccccccccc}
\hline & C1 & C2 & C3 & C4 & C5 & C6 & C7 & C8 & C9 & C10 & C11 & C12 & C13 & C14 & C15 \\
\hline C1 & - & 0.00 & 0.00 & 0.00 & 0.00 & 0.00 & 0.00 & 0.00 & 0.00 & 0.00 & 0.00 & 0.00 & -0.22 & 0.00 & 0.00 \\
C2 & 0.00 & - & 0.00 & 0.00 & 0.00 & 0.00 & 0.00 & 0.00 & 0.00 & 0.00 & 0.00 & 0.00 & 0.00 & 0.00 & -0.24 \\
C3 & 0.25 & 0.22 & - & 0.00 & 0.00 & 0.00 & 0.00 & -0.23 & 0.00 & 0.00 & -0.21 & 0.00 & 0.00 & 0.00 & 0.00 \\
C4 & 0.00 & 0.00 & 0.20 & - & 0.00 & 0.00 & 0.00 & 0.00 & 0.00 & 0.00 & 0.00 & 0.00 & 0.00 & 0.00 & 0.00 \\
C5 & 0.25 & 0.22 & 0.00 & -0.20 & - & 0.00 & 0.00 & 0.00 & 0.00 & 0.00 & -0.21 & 0.00 & 0.00 & 0.00 & 0.00 \\
C6 & 0.26 & 0.23 & 0.00 & -0.20 & 0.00 & - & 0.00 & 0.00 & 0.00 & -0.23 & 0.00 & 0.00 & 0.00 & 0.00 & -0.28 \\
C7 & 0.23 & 0.00 & 0.00 & 0.00 & 0.00 & 0.00 & - & 0.20 & 0.00 & 0.00 & 0.20 & 0.00 & 0.00 & 0.00 & 0.00 \\
C8 & 0.00 & 0.00 & 0.00 & 0.00 & 0.23 & 0.24 & 0.00 & - & 0.00 & 0.00 & 0.00 & 0.00 & 0.22 & 0.00 & 0.00 \\
C9 & 0.00 & 0.00 & 0.00 & 0.00 & 0.00 & 0.00 & 0.00 & 0.00 & - & 0.00 & 0.00 & 0.00 & 0.00 & 0.00 & 0.00 \\
C10 & 0.00 & 0.00 & 0.22 & 0.00 & 0.22 & 0.00 & -0.20 & 0.00 & 0.00 & - & 0.00 & 0.00 & 0.00 & 0.00 & 0.00 \\
C11 & 0.00 & 0.00 & 0.00 & 0.00 & 0.00 & -0.23 & 0.00 & 0.00 & 0.00 & 0.00 & - & 0.00 & 0.00 & 0.00 & 0.00 \\
C12 & 0.00 & 0.00 & 0.00 & 0.00 & 0.00 & 0.00 & 0.00 & 0.00 & 0.00 & 0.00 & 0.00 & - & 0.00 & 0.00 & 0.00 \\
C13 & 0.00 & 0.00 & 0.00 & 0.00 & 0.00 & 0.00 & 0.00 & 0.00 & 0.00 & 0.00 & 0.00 & 0.00 & - & 0.00 & -0.33 \\
C14 & 0.00 & 0.00 & 0.00 & 0.00 & 0.00 & 0.20 & 0.00 & 0.00 & 0.00 & 0.00 & 0.00 & 0.00 & 0.00 & - & -0.20 \\
C15 & 0.20 & 0.00 & 0.31 & 0.21 & 0.31 & 0.00 & -0.26 & 0.00 & 0.27 & 0.23 & 0.29 & 0.29 & 0.00 & 0.00 & - \\
\hline
\end{tabular}

Table 5. Final matrix of success

\subsubsection{Plotting the Concepts}

In order to define which factors have a greater influence on sustainability in the laboratory supply chain, node centrality is used. The node centrality is constructed by two measures: in-degree and out-degree. In-degree defines the number of links coming to the node, while out-degree defines the number of links coming from the node. There were four zones or quadrants formed: high indegree-high outdegree (Q1), high indegree-low outdegree (Q3), low indegree-high outdegree $(\mathrm{Q} 2)$, and low indegree- low outdegree (Q4). The most important factor is located in Q1 because it is located in the most central position.

\section{Results and Discussion}

\subsection{Causal Model Result}

The identified sustainable supply chain concepts for the laboratory would then be weighted using the triangular intuitionistic fuzzy number to develop a causal model. To label the relationship strength, then a classification is used, that is "no correlation" label that has value 0 , weak correlation label that has value 1 , moderate correlation label that has value 3, and strong correlation label that has value 9 (Franceschini \& Rupil, 1999). In order to focus only on the significant relationship between each concept, the construction of the final matrix uses a threshold of 0.20 that is obtained from the value above a "weak correlation" divided by a "strong correlation" that will result 
$1 / 9$, as the threshold of the considerable concepts. Hence, a relationship value below 0.20 was eliminated. The final causal model of sustainable supply chain management for the laboratory is depicted in Figure 2.

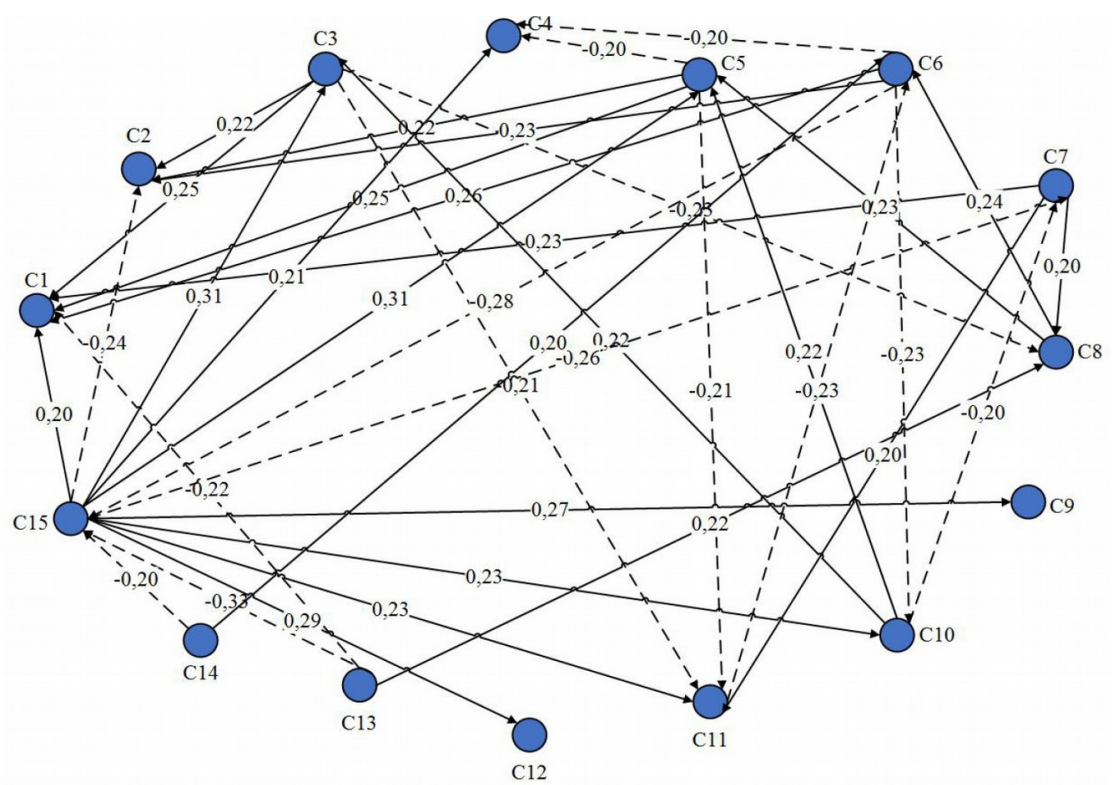

Figure 2. Causal model of laboratory sustainable supply chain management

Based on the causal model, it can be seen that the behavior of each concept has a causal dependence on other concepts. To achieve sustainability in its supply chain, this model illustrates that the laboratory needs to give more attention to Legal Requirements (C15) and Social Responsibility (C6) concept. Technically, the laboratory needs to declare clearly in documents about energy efficiency and the laboratory existence when giving good quality services to customers. Besides, giving attention to every complaint from customers for further improvement is also required.

\subsection{Node Plotting}

The output is used to plot the causal model using the centrality of nodes for further static analysis. For better interpretation, the results are plotted in four quadrants, as shown in Figure 3.

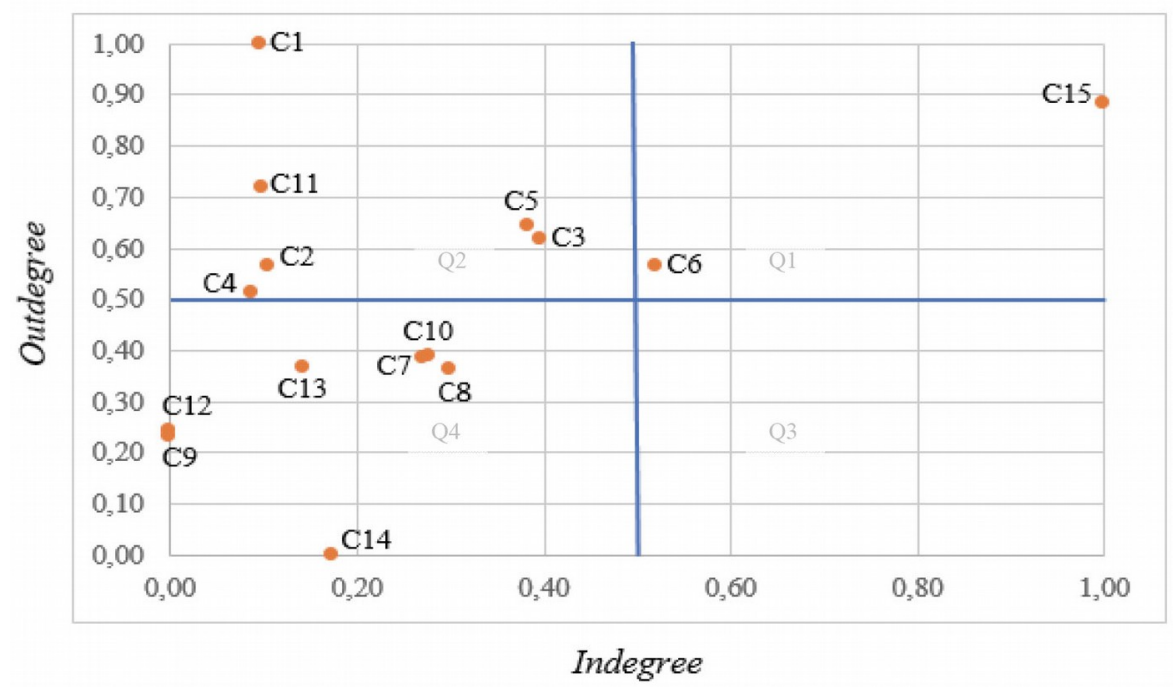

Figure 3. Nodes plotting in four quadrants 
The 15 concepts were then classified into four quadrants, which are explained as follows:

- Quadrant 1: this quadrant consists of concepts with high both outdegree and indegree. C6 and C15 are in this quadrant. Concepts that fall in this quadrant are required to be carefully administered in order to have sustainable laboratory supply chain management.

- Quadrant 2: this quadrant contains concepts with a high outdegree- low indegree value. C1, C2 C3, C4, C5, and $\mathrm{C} 11$ are in this quadrant. The importance of these quadrants lies in their high potential for causing improvement in the laboratory supply chain; hence, particular attention should be given to the concepts in this quadrant.

- Quadrant 3: this quadrant contains concepts with a low outdegree and high indegree value. Because of the high indegree value, the concepts under this quadrant are difficult to manage. However, this study does not produce any concepts that lie in this quadrant.

- Quadrant 4: this quadrant contains concepts with a low outdegree and indegree. The concepts in this quadrant do not have high implications to laboratory management and are less preconceived to be improved. In this study, concepts C7, C8, C9, C10, C12, C13, and C14 are in this quadrant.

Generally, there are two main drivers in sustainable supply chain management (Grosvold, Hoejmose \& Roehrich, 2014; Haverkamp, Bremmers \& Omta, 2010): external and internal. In this study, the two most important concepts were included in the external drivers: legal requirement under regulatory pressures and social responsibility under societal pressure. Legal requirement is the main foundation in the establishment of laboratory in the university because without fulfilling the legal requirement, the university laboratory will not be sustained. Legal requirements include waste management, establishment permits, and energy efficiency, etc. This is consistent with the research conducted by (Ansari \& Kant, 2017), who have summarized 92 sustainable supply chain management framework articles and found that legal requirement is the most frequent and important factor to be considered. Many organizations start implementing sustainable initiatives to avoid the disadvantages of penalties by the government. Legislation helps raise sustainability understanding and encourages organizations to implement sustainable practices (Saeed \& Kersten, 2019). Failure to comply with regulations can result in fines and barriers to trade.

Generally, higher education laboratories should conform to at least three legal requirements in the early establishment, which include regulation of energy, organizations permit from authorized institutions, and waste management for laboratories that produce toxic and hazardous waste. In Indonesia case, all regulations were written in the government law, such as the law number 30 year 2007 on energy, law number 101 year 2014 on toxic and hazardous waste, and Ministry of Education Law number 139 year 2014 on statue guidelines and higher education organization. The most severe sanctions for violating these regulations are the revocation of operational licenses.

The next most important concept is social responsibility (c6), which includes complaint handling ability and responsiveness to complaints. It covers responsibility for customers (student), end consumers (corporations and society), and suppliers (study programs or departments). Students might not be satisfied with their scores, unclear explanations from the laboratory assistant, lab facility availability, and unclear module. From the supplier perspective, the possible complaints are research output quality and student's satisfaction. However, from the end consumers perspective, the complaint is regarding to the employability, student job readiness, and student's skill.

The laboratory in higher education plays a major role in student's practical skills and knowledge development. The laboratory is a place where students enhance their understanding and learning of the laboratory skills needed for employability (Hunt, Koenders \& Gynnild, 2012). Great complaint management is a key success of consumer's retention and satisfaction in the service industry (Hansemark \& Albinsson 2004). The level of importance will be even greater in private higher education, where employability rates is the marketing strategy to get more students and profit (Farenga \& Quinlan, 2016).

Several methodologies have been developed by other researchers to decide the most important factors in the service supply chain management, as for instance: analytical network process (Tseng et al., 2018), confirmatory factor analysis (Hussain, et al., 2015) balance scorecard (Nouri, et al., 2018), and structural equation modelling (Xu \& Gursoy, 2015). However, the combination of Delphi and IFCM methods in this study could solve issues related 
to the doubts of experts on the basis of insufficient information available and give greater insight into the issue of sustainability in the service supply chain.

\section{Conclusion}

The performance of the service industry was left behind compared to the manufacturing industry. Most of the researchers believe that this was due to the ability of each sector in manage their supply chain. However, most of the study was much focus on the manufacturing sector instead of the service industry because of the higher variety and complexity of the service industry supply chain. Several frameworks, along with the concepts and indicators, have been developed to help the service industry assess their company's performance and be more sustainable in their business. Because of their specificity, researchers have built a sustainable supply chain framework in various and specific sectors: hospitality, airplane, hospital, bank, etc. Nonetheless, a sustainable supply chain framework in the education sector focusing in the university laboratories is still lacking.

In this study, we identified 15 main concepts influencing the sustainability of university laboratory supply chain management by conducting in-depth interviews with experts and addressing ambiguity among expert's opinions, and finally developed a causal model. Every business sector in the service industry may have different concern in determining the most important factor to keep their business sustainable. As for instance, in the healthcare industry, the most important factor is service management (Mirghafoori et al., 2018). While in the electronic design company, the most important factor is environmental service operation design (Tseng et al., 2018). Nonetheless, in this study, legal requirement and social responsibility became the most important factors for higher education in achieving sustainability in their business.

The contribution of this study is the factors that can help university laboratories achieve their sustainability in their business. This study also used the IFCM method to give greater insight into the issue of sustainability in the university laboratory supply chain. The proposed model could be adopted by other university laboratories in general to assess their current performance and to identify which factors should be paid more attention. Therefore, the university laboratory as a subunit in the higher education institution would achieve their sustainability in the business and be more competitive.

However, this study has several limitations. First, the number of respondents, this research is collected the data from seven experts and professional opinion, and the second is location, where this research is only conducted in one prominent private university in Indonesia. It is recommended to add more respondents to more than 15 , as suggested by Mirghafoori et al., (2018) and Tseng et al., (2018). Future research also suggested to enhance the research area, not limited to Yogyakarta, Indonesia, but also across cities, provinces, and countries to get an overall framework for education supply chain management and the critical enabler.

\section{Declaration of Conflicting Interests}

The authors declared no potential conflicts of interest with respect to the research, authorship, and/or publication of this article.

\section{Funding}

The authors received no financial support for the research, authorship, and/or publication of this article.

\section{References}

Ansari, Z. N., \& Kant, R. (2017). Exploring the Framework Development Status for Sustainability in Supply Chain Management: A Systematic Literature Synthesis and Future Research Directions. Business Strategy and the Environment, 26(7), 873-892. https://doi.org/10.1002/bse.1945

Atanassov, K.T. (1986). Intuitionistic Fuzzy Sets. Fuz:y Sets and Sytems, 20, 87-96. https://doi.org/10.1016/S01650114(86)80034-3

Axelrod, R. (1976). Cognitive Mapping Approach to Decision Making. In Structure of Decision: The Cognitive Maps of Political Elites (3-17). Princeton University Press. https://doi.org/10.1515/9781400871957-004 
Cho, D.W., Lee, Y.H., Ahn, S.H., \& Hwang, M.K. (2012). A framework for measuring the performance of service supply chain management. Computers \& Industrial Engineering, 62, 801-818. https://doi.org/10.1016/j.cie.2011.11.014

Cooper, M.C., \& Ellram, L.M. (1993). Characteristics of Supply Chain Management and the Implications for Purchasing and Logistics Strategy. The International Journal of Logistics Management, 4(2), 13-24.

https://doi.org/10.1108/MBE-09-2016-0047

Dursun, M., \& Gumus, G. (2020). Intuitionistic Fuzzy Cognitive Map Approach for the Evaluation of Supply Chain Configuration Criteria. Mathematical Methods in the Applied Sciences. https://doi.org/10.1002/mma.6238

Esfahbodi, A., Zhang, Y., \& Watson, G. (2016). Sustainable supply chain management in emerging economies: Trade-offs between environmental and cost performance. International Journal of Production Economics, 181, 350-366. https://doi.org/10.1016/j.ijpe.2016.02.013

Farenga, S.A., \& Quinlan, K.M. (2016). Classifying university employability strategies: three case studies and implications for practice and research. Journal of Education and Work, 29(7), 767-787. https://doi.org/10.1080/13639080.2015.1064517

Franceschini, F., \& Rupil, A. (1999). Rating scales and prioritization in QFD. International Journal of Quality and Reliability Management, 16(1), 85-97.

Giannakis, M. (2011). Management of service supply chains with a service-oriented reference model: the case of management consulting. Supply Chain Management: An International Journal, 16(5), 346-361. https://doi.org/10.1108/13598541111155857

Grosvold, J., Hoejmose, S.U., \& Roehrich, J.K. (2014). Squaring the circle: Management, measurement and performance of sustainability in supply chains. Supply Chain Management, 19(3), 292-305. https://doi.org/10.1108/SCM-12-2013-0440

Hansemark, O.C., \& Albinsson, M. (2004). Customer satisfaction and retention: The experiences of individual employees. Managing Service Quality: An International Journal, 14(1), 40-57. https://doi.org/10.1108/09604520410513668

Haverkamp, D.J., Bremmers, H., \& Omta, O. (2010). Stimulating environmental management performance: Towards a contingency approach. British Food Journal, 112(11), 1237-1251. https://doi.org/10.1108/00070701011088223

Hunt, L., Koenders, A., \& Gynnild, V. (2012). Assessing practical laboratory skills in undergraduate molecular biology courses. Assessment and Evaluation in Higher Education, 37(7), 861-874. https://doi.org/10.1080/02602938.2011.576313

Hussain, M., Khan, M., \& Al-aomar, R. (2016). A framework for supply chain sustainability in service industry with Confirmatory Factor Analysis. Renewable and Sustainable Energy Reviews, 55, 1301-1312. https://doi.org/10.1016/j.rser.2015.07.097

Ke, D., Song, Y, \& Quan, W. (2018). New Distance Measure for Atanassov's Intuitionistic Fuzzy Sets and Its Application in Decision Making. Symmetry, 10(10), 429. https://doi.org/10.3390/sym10100429

Liu, W., Bai, E., Liu, L., \& Wei, W. (2017). A Framework of Sustainable Service Supply Chain Management: A Literature Review and Research Agenda. Sustainability (Switzerland), 9(3), 1-25. https://doi.org/10.3390/su9030421

Lu, A., \& Ng, W. (2005). Vague Sets or Intuitionistic Fuz:y Sets for Handling Vague Data: Which One Is Better? In Delcambre L., Kop C., Mayr H.C., Mylopoulos J., \& Pastor O. (Eds). Conceptual Modeling - ER 2005. ER 2005. Lecture Notes in Computer Science (3716). Springer, Berlin, Heidelberg. https://doi.org/10.1007/11568322_26

Mirghafoori, S.H., Sharifabadi, A.M., \& Takalo, S.K. (2018). Development of Causal Model of Sustainable Hospital Supply Chain Management Using the Intuitionistic Fuzzy Cognitive Map (IFCM) Method. Journal of Industrial Engineering and Management, 11(3), 588-605. https://doi.org/10.3926/jiem.2517 
Nouri, F.A., Nikabadi, M.S., \& Olfat, L. (2019). Developing the framework of sustainable service supply chain balanced scorecard (SSSC BSC). International Journal of Prouctivity and Performance Management, 68(1), 148-170. https://doi.org/10.1108/IJPPM-04-2018-0149

Saeed, M.A., \& Kersten, W. (2019). Drivers of Sustainable Supply Chain Management: Identification and Classification. Sustainability (Switzerland), 11(4), 1137-1160. https://doi.org/10.3390/su11041137

Tseng, M., Lim, M.K., Wong, W., Chen, Y., \& Zhan, Y. (2018). A framework for evaluating the performance of sustainable service supply chain management under uncertainty. International Journal of Production Economics, 195, 359-372. https://doi.org/10.1016/j.ijpe.2016.09.002

Tseng, M.L., Lin, S., Chen, C.-C., Calahorrano Sarmiento, L.S., \& Tan, C.L. (2019). A causal sustainable product-service system using hierarchical structure with linguistic preferences in the Ecuadorian construction industry. Journal of Cleaner Production, 230, 477-487. https://doi.org/10.1016/j.jclepro.2019.05.140

van Ark, B., O’Mahony, M., \& Timmer, M.P. (2008). The productivity gap between Europe and the United States. Journal of Economic Perspectives, 22(1), 24-44. https://doi.org/10.1257/jep.22.1.25

Xu, X., \& Gursoy, D. (2015). Influence of sustainable hospitality supply chain management on customers' attitudes and behaviors. International Journal of Hospitality Management, 49, 105-116. https://doi.org/10.1016/j.ijhm.2015.06.003

Journal of Industrial Engineering and Management, 2020 (www.jiem.org)

\section{(c) (1) (\$)}

Article's contents are provided on an Attribution-Non Commercial 4.0 Creative commons International License. Readers are allowed to copy, distribute and communicate article's contents, provided the author's and Journal of Industrial Engineering and Management's names are included. It must not be used for commercial purposes. To see the complete license contents, please visit https://creativecommons.org/licenses/by-nc/4.0/. 